International Journal of Current Advanced Research

ISSN: O: 2319-6475, ISSN: P: 2319-6505, Impact Factor: 6.614

Available Online at www.journalijcar.org

Volume 7; Issue 4(G); April 2018; Page No. 11773-11776

DOI: http://dx.doi.org/10.24327/ijcar.2018.11776.2050

Research Article

\title{
NERVE STIFFNESS - A CHALLENGE FOR ULTRASOUND ELASTOGRAPHY
}

\section{Sava Stajic ${ }^{1}$, Aleksandar Vojvodic ${ }^{2}$, Luis Perez Carro ${ }^{3}$., Milos Gasic., ${ }^{4}$ Ana Mladenovic Markovic ${ }^{5}$ and Gordana Lukic ${ }^{1}$}

${ }^{1}$ Clinical Hospital Center "Dr Dragisa Misovic", Department of Diagnostic Radiology, Belgrade, Serbia

${ }^{2}$ Clinical Hospital Center "Zemun", Department of Orthopedic Surgery, Belgrade, Serbia

${ }^{3}$ Hospital Clinica Mompia, Santa Cruz de Bezana, Santander, Spain

${ }^{4}$ Institute of Anatomy, Faculty of Medicine, University of Kosovska Mitrovica,

${ }^{5}$ Clinical Center of Serbia, Institute od Diagnostic Radiology, Belgrade, Serbia, Pasterova 2, 11000 Belgrade, Serbia

${ }^{1}$ Clinical Hospital Center "Dr Dragisa Misovic", Department of Diagnostic Radiology, Belgrade, Serbia

\section{A R T I C L E I I N F O}

\section{Article History:}

Received $13^{\text {th }}$ January, 2018

Received in revised form $24^{\text {th }}$

February, 2018 Accepted $9^{\text {th }}$ March, 2018

Published online $28^{\text {th }}$ April, 2018

\section{Key words:}

Nerve stiffness, Sonoelastography, Sciatic Nerve, Deep Gluteal Syndrome

\begin{abstract}
A B S S T R A A C T
Nerve stiffness associated with limb movements was a challenge for sonoelastography in the diagnosis of sciatic nerve entrapment in deep gluteal syndrome. The sciatic nerve was scanned by ultrasound strain elastography, during limb movements, in healthy persons (62) and in patients with deep gluteal syndrome (108). The results were presented by "B" mod, color maps and strain ratio. In flexion movements sciatic nerve diameters were statistically significantly lower, than in extension movement in both groups $(p<0.001)$. Patients with deep gluteal syndrome, had significantly lower diameters of sciatic nerves $(p<0.001)$, than the healthy group of persons. The group of healthy persons had significant increase of strain value $(p<0.001)$ from extension to flexion movement of leg. The group of patients with deep gluteal syndrome had significant increase of strain value $(p<0.001)$ in extension and in flexion movement of leg, than the healthy persons. In deep gluteal syndrome the specificity of method was $93.5 \%$. sensitivity was $88.9 \%$, with accuracy of $90.6 \%$. Strain elastography imaging is currently the only diagnostic procedure based on the assessment of nerve stiffness with crucial information about the degree of nerve entrapment.
\end{abstract}

Copyright $(2018$ Sava Stajic et al. This is an open access article distributed under the Creative Commons Attribution License, which permits unrestricted use, distribution, and reproduction in any medium, provided the original work is properly cited.

\section{INTRODUCTION}

Changes in periferal nerve stiffness, associated with tightening and relaxing, during limb movements, may be important in understanding various nerve diseases, as deep gluteal syndrome. Miller and Cass believed that deep gluteal syndrome is a result of sciatic nerve compression caused by piriformis muscle $(14,2)$. Symptoms vary and can include pain and numbness down the leg (Cass and Liebert) and are worsened with sitting or running $(2,11)$. The radiographs and the MRI image of the lumbar spine and pelvis showed no pertinent findings, by Martin and Michel $(12,13)$.

Authors Andrade, Greening (2016,2017), Santos, Ellis (2015,2018), Neto and Dikici reffered that elastography was applied $(1,3,4,5,6,7,15$ and 17$)$ to develop diagnostic possibilities and improve therapeutic modalities. The full testing of sciatic nerve during limb movements have not been examined in detail, but Andrade and Ellis noticed sciatic nerve tightening with ankle and knee movements $(1,5)$.

\section{*Corresponding author: Sava Stajic}

Clinical Hospital Center "Dr Dragisa Misovic", Department of Diagnostic Radiology, Belgrade, Heroja MIlana Tepica 1, 11000 Belgrade, Serbia
The morphological changes of sciatic nerve during extension and flexion movements were observed, but elastography test of mechanical properties with sciatic nerve stiffness was the challenge. The aim of the study was to demonstrate relevance of strain elastography test in the diagnosis of sciatic nerve disease.

\section{MATERIAL AND METHODS}

The sciatic nerve was scanned during limb movements in two groups of people, in asymptomatic healthy persons (62) and in symptomatic patiens with deep gluteal syndrome (108). The imaging was performed at the posterior thigh in both groups. The region of interest (ROI) was on sciatic nerve and up to pyriformis muscle. The nerve was typically visualized at a depth of 6 to $8 \mathrm{~cm}$ depending of field of view. By ultrasonography, sciatic nerve was visualized as a hyperechoic, slightly flat oval and striped structure. The strain elastography results were presented by color maps and relative strain ratio. Nerve excursions were measured in transverse and longitudinal planes during extension and flexion movement.

The sciatic nerve was scanned using ultrasound elastography equipments (Toshiba Aplio 300 and GE Logiq S8). The strain elastography diagnostic imagings were performed by two 
types of probes, linerar ( 5 to $10 \mathrm{MHz}$ ), and curved one (3 to $5 \mathrm{MHz}$ ) for visuelization of deep parts. That method requires the probe force application by compression-decompression repeated test. The tissue displacement resulted in color map, and the calcualtion of the strain ratio (SR) was between different ROI's (region of interest). In strain elastography of sciatic nerve special attention was focused at pre compression force.Obtained data were analyzed using SPSS software (version 22.0 for Windows). The measures of central tendency (arithmetic mean, median), measurements of variability (standard deviation) and relative numbers (structural indicators) were used. The Pearson linear correlation coefficient was used for the analysis of dependence. Statistical hypotheses were tested at the level of statistical significance (alpha level) of 0.05 . Finally ROC analysis was performed.

\section{RESULTS}

In the healthy group, as in the group with deep gluteal syndrome, during limb movements, diameters of sciatic nerve changed. In flexion movement diameters were statistically significantly lower, than in extension movement $(p<0.001)$. In the course of the extension movement, patients with deep gluteal syndrome, had significantly lower diameters of sciatic nerves than the healthy group of persons.

Table 1 Diameters of sciatic nerve (mm)

\begin{tabular}{|c|c|c|c|c|c|c|}
\hline Patients & $\mathbf{x}^{-}$ & sd & Cut off & $\min$ & $\max$ & p-value \\
\hline $\begin{array}{c}\text { Sciatic nerve } \\
\text { extension in healthy } \\
\text { persons (62) }\end{array}$ & 8.21 & 0.54 & 9.29 & 7.3 & 9.2 & \\
\hline $\begin{array}{l}\text { Sciatic nerve } \\
\text { flexion in healthy } \\
\text { persons }(62)\end{array}$ & 4.7 & 0.29 & 5.28 & 4.3 & 5.8 & \\
\hline $\begin{array}{c}\text { Sciatic nerve } \\
\text { extension in deep } \\
\text { gluteal syndrome } \\
(108)\end{array}$ & 5.86 & 0.74 & & 4.1 & 7.1 & $<0,001$ \\
\hline $\begin{array}{c}\text { Sciatic nerve } \\
\text { flexion in deep } \\
\text { gluteal syndrome } \\
(108)\end{array}$ & 4.3 & 0.68 & & 1.7 & 6.1 & $<0,001$ \\
\hline
\end{tabular}

The group of healthy persons had strain ratio of $1.32 \mathrm{SR}$ in extension movement of the leg, with significant increase $(p<0.001)$ in flexion movement of leg $(4.27 \mathrm{SR})$. The group of patients with deep gluteal syndrome had strain value of $6.38 \mathrm{SR}$ in extrension movement of leg, with significant increase $(p<0.001)$ in flexion movement of leg, 10.54SR. The cut off strain ratio in extension movement was $2.78 \mathrm{SR}$, and in flexion movement was $5.75 \mathrm{SR}$.

Table 2 The strain ratio (SR) of sciatic nerve

\begin{tabular}{ccccccc}
\hline Patients & $\mathbf{x}^{-}$ & sd & Cut off & min & max & p-value \\
\hline $\begin{array}{c}\text { Sciatic nerve } \\
\text { extension in healthy } \\
\text { persons (62) }\end{array}$ & 1.32 & 0.73 & 2.78 & 0.7 & 4.1 & \\
$\begin{array}{c}\text { Sciatic nerve } \\
\text { flexion in healthy } \\
\text { persons (62) } \\
\text { Sciatic nerve }\end{array}$ & 4.27 & 0.74 & 5.75 & 2.8 & 5.7 & \\
$\begin{array}{c}\text { extension in deep } \\
\text { gluteal syndrome } \\
\quad(108)\end{array}$ & 6.38 & 2.83 & & 1.9 & 15.9 & \\
$\begin{array}{c}\text { Sciatic nerve } \\
\text { flexion in deep } \\
\text { gluteal syndrome } \\
\quad(108)\end{array}$ & 10.54 & 2.98 & & 3.7 & 13.4 & $<0,001$ \\
\hline
\end{tabular}

By ROC analysis the specificity of ultrasound elastography in patients with deep gluteal syndrome was $93.5 \%$, the sensitivity was overall $88.9 \%$, with the accuracy $90.6 \%$. The positive predictive value was $82.6 \%$, while the negative predictive value was $96 \%$.

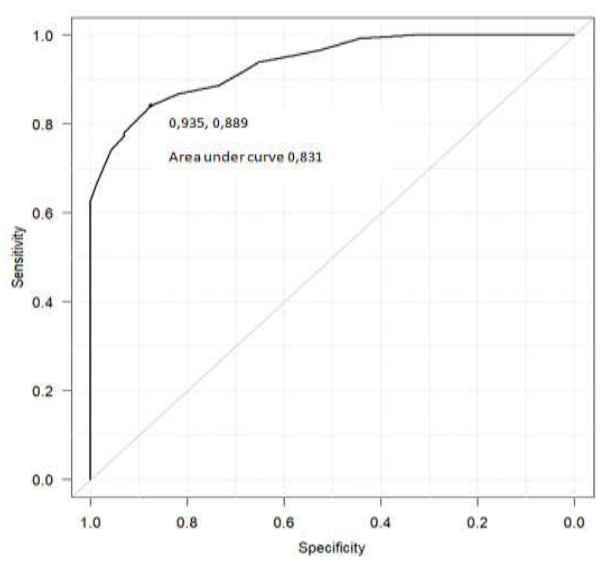

By color map in healthy persons during extension movements sciatic nerve colored in green and yellow, while during flexion movement sciatic nerve was predominantly with blue color coded areas. In the group with deep gluteal syndrome during extension movement sciatic nerve was more blue than green colored, and in flexion movements the sciatic nerve was predominantly blue and grey colored.

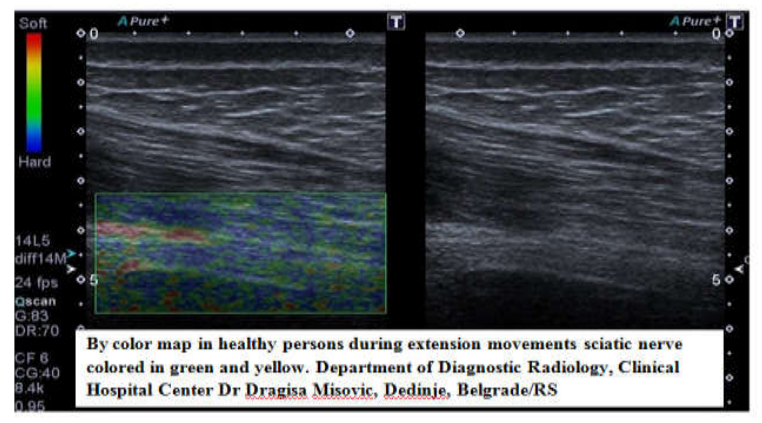

Fig. 2

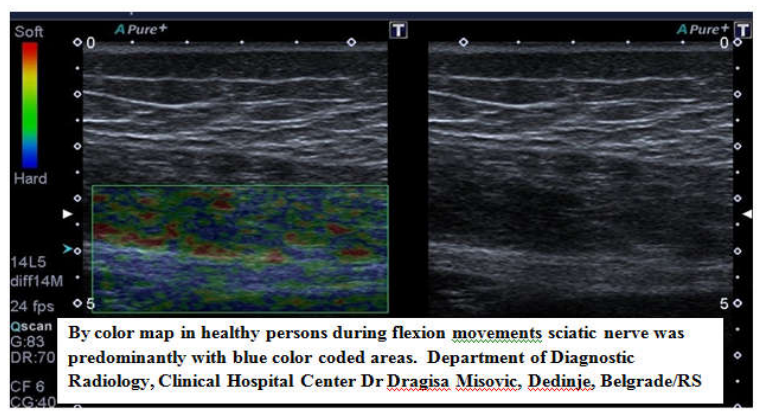

Fig. 3

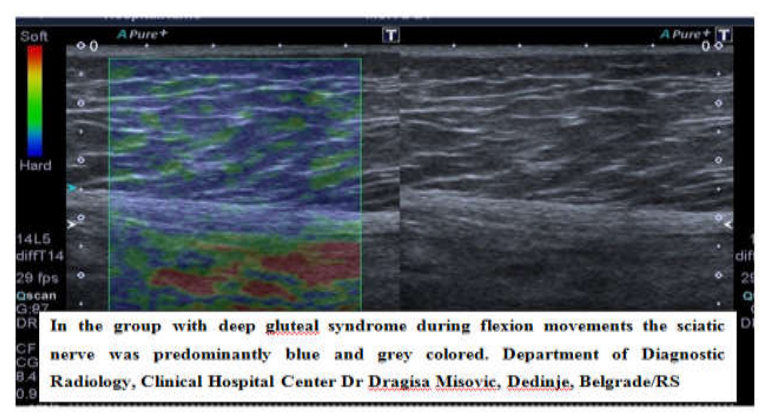

Fig. 4 
The Pearson linear correlation coefficient was used for the analysis of dependence. The correlation coefficient between sciatic nerve diameters and between sciatic nerve strain ratio was significant in both groups during extension and flexion movements $(\mathrm{r}=0.510$ and $\mathrm{r}=0.754)$. The correlation coefficient between sciatic nerve diameter and strain ration during extension movements was also most significant with $\mathrm{r}=0.784$.

The strain elastography of sciatic nerve in patients with deep gluteal syndrome was performed as preoperative test.

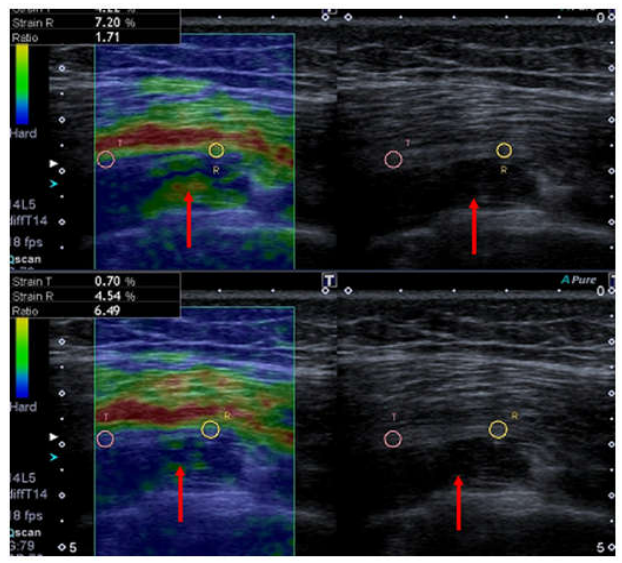

Fig. 5 The strain elastography of sciatic nerve in symptomatic leg pain patients with tags near m.piriformis (red arrow), during the les extension (1,7 SR) and flexion (6,49 SR) (preoperative test). Department of Diagnostic Radiology, Cl
Dragisa Misovic, Dedinje, Belgrade/RS
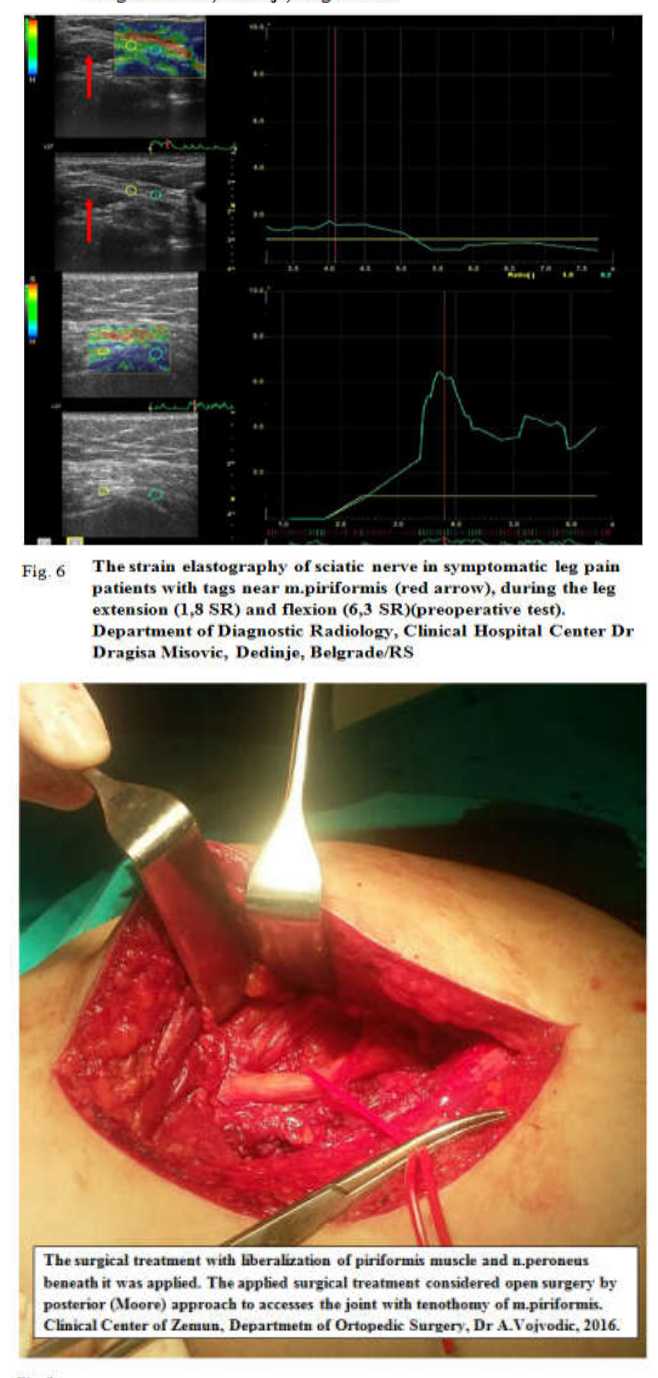

Fig 7
Upon surgical exploration of the sciatic nerve, a fibrotic tendinous scar beneath the piriformis muscle was found and released.

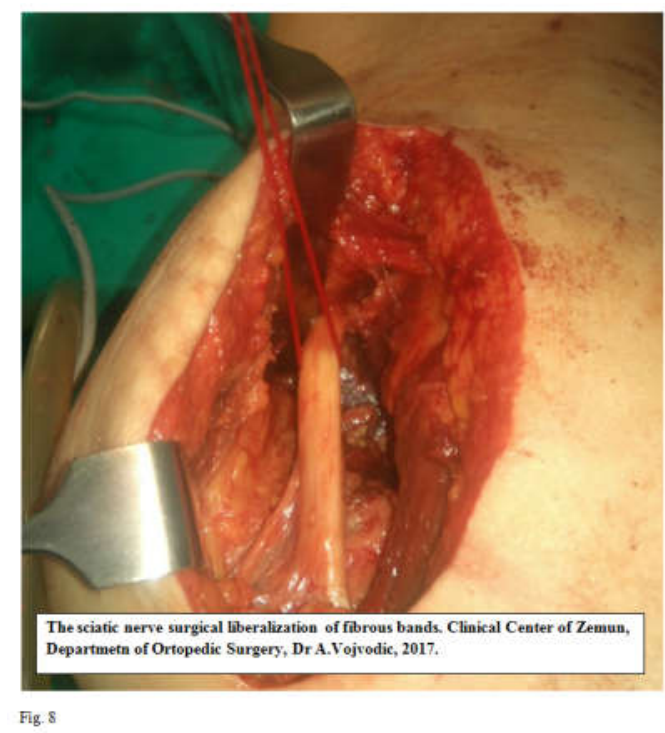

\section{DISCUSSION}

In our investigation strain elastrography have shown high and very usefull operating characteristics by ROC analysis $(1,7)$. This can be explained by shortening of sciatic nerve diameter during the flexion. During such a movement, the nerve was tense, and the strain ratio raised up.

In healthy persons sciatic nerves was freely stressed and relaxed in repeted test. The shortening of the nerve diameter with the increased strain ratio in sciatic nerve flexion movement was observed. The specificity was representative.

The fibrous bands with nerve entrapment in patients with deep gluteal syndrome significantly decreased the diameter of sciatic nerve in extension, and sciatic nerve flexion movement, as the result of nerve tightening $(1,4,5)$. It was observerd that movement resulted in the increased nerve stiffness (with increased strain ratio).

The color coded maps were not particularly helpful, due to the fact that there was a precompression, and sciatic nerve was typically visualized at a depth of 6 to $8 \mathrm{~cm}$. This limitation is a challenge and suggests a need for further research. In four patients with deep gluteal syndrome there were marked increased sciatic nerve strain ratio during extension, followed by slight decrease of values in flexion. This can be explained with massive fibrous bands (found by operative findings), with paradoxal relax in flexion.

The prevalence of female population was represented by clinically confirmed cases. Looking at the age there were no differences in sciatic nerve diameter. In effort to stadardize the elastography test, it was shown that the differencies beetwen surrounding muscle's structure and sciatic nerve are more compresed dependent, than the differences of intraneural stiffness, especially seen in the morfological changes of nerves and surronding fibrous processes in symptomatic patients. Therefore the position of ROI was marked up to priformis muscle structure. The resection was done from trochanter's attachment, by separation of joint tendon of m.piriformis and m.obturator internus, and by release of n.peroneus and 
n.tibialis from fibrous bands and surrounding muscles (Hopayian, Hernando and Perez Carro, 14-17). The study was limited by the technology used and depended on external probe force, ultrasound equipment, the position of ROI and by colour maps. We are going to systematize the approach by depth of field, in order to identify the exact area of referent tissue, and to obtain the referent colour map. The application of new technological advances allowed more accurate reproducible strain elastography results in preoperative processing.

\section{CONCLUSIONS}

The variation of sciatic nerve is challenging for diagnostic and therapeutic procedure in many clinical and surgical cases. Quick recognition of sciatic nerve makes surgical approaches more precise and effective, with better outcome. Ultrasound strain elastography images tend to be good and are currently the only diagnostic procedure that is based on the assessment of nerve stiffness, and this procedure can give us crucial information about the degree of nerve entrapment.

\section{References}

1. Andrade RJ, Nordez A, Hug F, et al. Non-invasive assessment of sciatic nerve stiffness during human ankle motion using ultrasound shear wave elastography. $J$ Biomech 2016;3:326-331.

2. Cass SP. Piriformis syndrome: a cause of nondiscogenic sciatica. Current sports medicine reports.14;1:41-44.

3. Dikici AS, Ustabasioglu FE, Delil S, et al. Evaluation of the Tibial Nerve with Shear-Wave Elastography: A Potential Sonographic Method for the Diagnosis of Diabetic Peripheral Neuropathy. RSNA 2017;282:2.

4. Ellis R, Fox J, Hitt JR, Langevin H, Henry SM. Examining the mechanical influences upon the sciatic nerve at the sciatic nerve-hamstring muscle interface during active and passive knee extension. TUWERA Open Research 2015, http://hdl.handle.net/10292/8737.

5. Ellis R, Rohan M, Fox J, Hitt J, Langevin H, Henri S. Ultrasound Elastographic Measurement of Sciatic Nerve Displacement and Shear Strain During Active and Passive Knee Extension. Journal of Ultrasound in Medicine, 2018, doi: https://doi.org/10.1002/jum.14560.
6. Greening J, Dilley A, Posture-induced changes in peripheral nerve stiffness measured by ultrasound shearwave elastography. Muscle \& Nerve 2016, doi: $10.1002 /$ mus. 25245 .

7. Greening J, Dilley A. Posture-induced changes in peripheral nerve stiffness measured by ultrasound shearwave elastography. Muscle and nerve 2017, doi:10.1002/mus.25245.

8. Hal DM, Shears SA, Johnson C, Smathers AM, Palmer IJ. The Endoscopic Treatment of Sciatic Nerve Entrapment/ Deep Gluteal Syndrome, Arthroscopy. The Journal of Arthroscopic and Related Surgery 2011;2:172-181.

9. Hernando MF, Cerezal L, Perez-Carro L. et al: Deep gluteal syndrome: anatomy, imaging, and management of sciatic nerve entrapments in the subgluteal space. Skeletal Radiology 2015;7:919-934.

10. Hopayian K, Danielyan A. Four symptoms define the piriformis syndrome: an updated systematic review of its clinical features. European journal of orthopaedic surgery \& traumatology: orthopedie traumatologie 2017, doi:10.1007/s00590-017-2031-8.

11. Liebert PL (eds). Piriformis Syndrome. Merck Manuals Professional Edition, 2014.

12. Martin HD, Reddy M, Gomez-Hoyos J. Evaluation of lower back muscle activity with functional magnetic resonance imaging. Journal of hip preservation surgery. 2015;2:99-107.

13. Michel F, Decavel P, Toussirot E, et al. The piriformis muscle syndrome: An exploration of anatomical context, pathophysiological hypotheses and diagnostic criteria. Annals of Physical and Rehabilitation Medicine 2013;56:300-311.

14. Miller TA, White KP, Ross DC. The diagnosis and management of Piriformis Syndrome: myths and facts. Canadian Journal of Neurological Sciences 39;5:577583.

15. Neto T,Freitas SR, Andrade RJ, et al. Sciatic nerve stiffness is not changed immediately after a slump neurodynamics technique. Muscles, Ligaments and Tendons Journal 2018, doi: 10.11138/mltj/2017.7.3.583.

16. Perez Carro, Hernando MF, Cerezal L et al: Deep gluteal space problems: piriformis syndrome, ischiofemoral impingement and sciatic nerve release. Muscle, Ligaments and tendons journal 2016;6:384-396.

17. Santos R, Armada P. Sciatic Nerve Hardness Measurement by Using Ultrasound Elastography. Ultrasound in medicine and biology 2013;5:S57.

\section{How to cite this article:}

Sava Stajic et al (2018) 'Nerve Stiffness - A Challenge for Ultrasound Elastography', International Journal of Current Advanced Research, 07(4), pp. 11773-11776. DOI: http://dx.doi.org/10.24327/ijcar.2018.11776.2050 